\title{
A Review of the Role of Assistive Technology for People with Dementia in the Hours of Darkness
}

\author{
W. Carswell", P.J. McCullagh"J.C. Augusto*, S. Martin ${ }^{\S}$, M.D. Mulvenna*, \\ H. Zheng ${ }^{*}$, H.Y. Wang ${ }^{*}$, J.G. Wallace ${ }^{*}$, K. McSorley ${ }^{\dagger}$, B. Taylor ${ }^{\dagger}$, and W.P. Jeffers ${ }^{\dagger}$ \\ School of Computing and Mathematics, University of Ulster, Northern Ireland, UK \\ [w.carswell, pj.mccullagh, jc.augusto, md.mulvenna, h.zheng, hy.wang, jg.wallace] @ulster.ac.uk \\ ${ }^{\S}$ School of Health Sciences, University of Ulster, Northern Ireland, UK \\ s.martin@ulster.ac.uk \\ ${ }^{\dagger}$ Fold Housing Association, Northern Ireland, UK \\ [kevinmcs, barbara.taylor, paul.jeffers]@ foldgroup.co.uk
}

\begin{abstract}
Assistive Technology (AT) has been utilized to support people with dementia (PwD) and their carers in the home. Such support can extend the time that PwD can remain safely at home, and reduce the burden on the tertiary healthcare sector. Technology can assist people in the hours of darkness as well as during the day. The objective of this literature review is to evaluate reported healthcare technologies appropriate to night time care. This paper summarises and categorises the current evidence base. In all, 131 abstracts were returned from a database search, yielding fifty four relevant papers which were considered in detail. While night-time specific studies identified very few papers (4 papers, 7\%), most of the more general AT findings can be adopted to benefit night-time assistance. Studies have used technology for prompting and reminding as loss of time and forgetfulness are major problems; for monitoring daily activities in a sensor enriched environment and utilised location aware technologies to provide information to enhance safety. Technology also supports a range of therapies to alleviate symptoms. Therapies include the delivery of music and familial pictures for reminiscing, the use of light therapy to enhance wellbeing and the provision of mental tasks to stimulate the brain and maintain activity levels.
\end{abstract}

Keywords: dementia, night-time care, therapeutic assistance, ambient assisted living.

\section{Introduction}

In 2000, there was a global population of 600 million people aged 60 or over which is due to increase to over 2 billion by 2050 [58]. Whilst people are living longer, more people are also experiencing cognitive problems, in particular dementia. Dementia is a term used to describe the symptoms of a group of illnesses that cause a progressive decline in a person's cognitive functioning [4]. Symptoms include loss of memory, intellect, rationality, social skills and normal emotional reactions. Nearly all dementias degrade memory once they become sufficiently advanced but in the earliest stages of some of the non-Alzheimer's disorders, the cognitive decline is characterized by other abnormalities of thinking, not necessarily involving memory [39]. 
The most common assessment tool for measuring mental state for PwD [64] is the Mini Mental State Exam (MMSE) [20], a set of questions focused around Orientation, Registration, Attention, Recall and Language [31]. Based on this assessment a score is calculated to demonstrate the person's general level of impairment. MMSE scores range from 0 , indicating severe Alzheimer's disease, to 30, indicating normal function. Whilst the MMSE is considered a generally reliable measure of cognitive impairment, evidence suggests highly educated people tend to score higher on the MMSE even when they do have Alzheimer's disease [41].

Ferri et al. [19] illustrated the scale of the potential future epidemic by postulating that 81.1 million people will be diagnosed with dementia by 2040. Even with people working longer than ever before, the global employment-to-population ratio has been decreasing steadily, $63.3 \%$ in 1993 to $61.1 \%$ in 2003 , which in turn provides service constraints, particularly in health support for the elderly and those with chronic disease [29, 54]. There has been a fundamental shift in healthcare policy in many first world economies to encourage and facilitate PwD to live longer at home, on the provision that their care situation is appropriate to need. We believe a major challenge for healthcare research will be to balance the lack of physical resources with a technological solution to aid PwD and their carers living at home and minimise potential hazards [17].

Technology may facilitate the decentralization of healthcare provision from secondary and tertiary care models and enable primary and community care to take the lead [43]. The US Assistive Technology Act of 1998 cited "assistive technology" to be technology used by individuals with disabilities in order to perform functions that might otherwise be difficult or impossible [1]. The UK King's Fund consultation meeting proposed the following definition: "Assistive Technology is any product or service designed to enable independence for disabled and older people" [18].

Whilst there has been significant research into independence benefits AT can bring to home life for $\mathrm{PwD}$, the focus has been on developing support services during what is considered the normal active period of the day, that is daytime. Night time activity levels may be lower but this is potentially a more vulnerable period for PwD and of particular concern to their carers. AT has been used to assist with the regulation of sleep patterns, as excessive daytime sleeping and Sundown syndrome contribute to the night-time problems [9]. Sundown syndrome (sundowning) is a term that describes the onset of confusion and agitation that generally affects $\mathrm{PwD}$ or cognitive impairment and strikes in the late afternoon or early evening (when the sun goes down). A closely related syndrome is that of day-night reversal [7] where PwD experience longer periods awake at night than they do during the day. Carers have to deal with the consequences of these disturbed patterns, which often requires awaking from their sleep to calm the PwD and try to get them back to bed. This provides significant additional burden to the carer.

This paper provides an analysis of the existing technology-based solutions proposed in the literature and suggests how those previous projects can relate to the night time period. The methodology for literature selection is defined in section 2 and findings are reviewed 
in section 3. A discussion, recommendations and conclusion are provided in sections 4, 5 and 6 respectively.

\section{Methods}

\subsection{Literature search strategy}

A search of AT literature was conducted on nine Internet searchable databases (Fig. 1). This provided coverage of the technical and healthcare literature.

The first phase involved a search using pre-set search criteria (Fig. 1) in order to identify papers which studied the use of AT in dementia and night time as the key components. The search terms were produced from discussions between health care professionals, professionals experience in delivering sheltered care in Northern Ireland, and computer scientist researchers with prior knowledge and expertise in developing health care AT. One hundred and thirty one papers were selected. Study selection was based upon reading and rating of abstracts returned from the above databases. A five level scoring system was used to determine relevance: (0: not, 1: little, 2: some, 3: good, 4: definite). An aggregate threshold score of 5 was required for both readers. This process yielded 54 papers.

A review and assessment was carried out on the full paper. Two assessors, an academic with expertise in AT and chronic disease management and a research associate, collaborated together in the knowledge extraction and classification. A taxonomy of the topics covered and classification of papers is provided in Table 1.

\subsection{Data extraction, analysis and assessment}

Each paper was categorised with descriptive information (journal title, time of day etc.) to show the main scope it covered (Table 2). Each reviewer wrote a short synopsis in their own words illustrating: type of experimentation, equipment used, what the study encompassed, the associated results/findings and conclusions. Upon completion of individual assessment the reviews were discussed to ensure agreement on the selected papers. Consortium expertise was sought on any difference of opinion. Fig 2 illustrates the distribution of paper categories.

\section{Review Findings}

There were three broad classifications identified; night specific $(\mathrm{N})$, night and day (N/D) and finally day applicable to the night time scenario $(D \rightarrow N)$. Fig. 3 illustrates the percentage breakdown of papers analysed.

\subsection{Night specific (N)}


Only four papers $(7.4 \%)$ were identified as night time specific. The topic areas relate to safety using technology for monitoring and guidance. Education of $\mathrm{PwD}$ and their carers was also addressed.

\subsubsection{Monitoring}

AT can be used to monitor PwD, assess the patterns and types of movement which can then help to provide information on mental and physical health. AT can also be used as a safety measure to call for help in the case of an emergency. Campo et al. [11] presented a monitoring system for PwD using an expert system. It was a non-intrusive system and did not require cameras, pendant or bracelet. The system tracked people and monitored their activities through use of low cost positioning sensors. The system recorded and learned the person's movements and their whereabouts. Seventeen people were monitored in a short-stay unit from 2 to 15 nights and a total of 83 nights. Thirteen had Alzheimer's disease. The system calculated mobility parameters (duration and frequency) over time intervals selected by the investigator. The following data were recorded: number of times he/she got up, went back to bed, visited the toilet, and left the bedroom, and the distance covered during the night. Such analysis could give nurses warning of an increased risk of fall or a decrease in mobility and assist them in making decisions on prescribing medication or whether additional surveillance was needed.

Schikhof et al. [50] designed a bedroom monitoring system using sensors, a camera and a microphone to capture information appropriate to activities of daily living (ADL). Although the approach was highly intrusive, the authors stated that ethical issues were not a problem, in this case, but of course one must consider the different ethical issues in other countries.

\subsubsection{Lighting and guidance}

At night time darkness and disorientation is a hazard. Therefore lighting for guidance is a very important aspect of safety. Lighting can guide PwD to destinations or make them aware of other hazards. Torrington et al. [55] produced a set of guidelines for the design of lighting in residential buildings. The study arose from two multi-disciplinary research projects for people with Alzheimer's disease. Design in Caring Environments (DICE, 2000-04), examined standards and guidelines for the design of care homes for older people. INDEPENDENT (2003-06), examined the role of technology in enhancing the well-being of PwD. In the report they suggested that lighting significantly assisted navigation by ensuring that different areas were visually distinct and providing orientating views. Effective lighting improved recognition of spatial awareness and visual orientation.

\subsubsection{Education and treatment}

Normal lifecycles revolve around patterns. In the cases for PwD, this cycle is usually disrupted. McCurry et al. [37] introduced a sleep education program (Nighttime Insomnia Treatment and Education for Alzheimer's Disease, NITE-AD) for PwD to try 
and improve sleep patterns at home. The NITE-AD program introduced the combination of sleep education, daily walking, and light exposure intervention over three weekly treatment sessions. The sleep education included brochures describing good sleep practices, sleep changes associated with normal aging and strategies for improving sleep in PwD. Treatment sessions included a 30 minute daily walking exercise and a program for increasing daily light exposure via a "Sun-Ray light box", within a 3 hour window of bed time. Results showed participants spent an average of 36 minutes less time awake at night and had 5.3 fewer nightly awakenings. After 6 months NITE-AD participants had significantly fewer awakenings per hour and were awake for less time at each awakening, thus assisting regulation of a more conducive circadian pattern.

\subsection{Night and day (N/D)}

More studies encompassed the night and day aspect compared to the night specific consideration. In total 14 papers, representing $25 \%$ of the articles analysed, were in this category (Fig. 3).

\subsubsection{Monitoring}

Wood et al. [61] proposed ALARM-NET, a wireless sensor network designed for longterm health monitoring in the assisted living and residential environments. A central design goal was to adapt the operation of the system, including power management and privacy policy enforcement, to the individual life patterns of the PwD. Dempster-Shafer evidential theory was used to process the combination of location, physiological data and learned activity patterns. Individual life patterns of the residents were analyzed and fed back to the users to promote awareness. The authors indicated that more research and testing was needed to validate the approach and hence warrant its introduction. Hori et al. [28] developed an ultrasonic sensor network system to remotely monitor the position of wheelchair bound PwD in a nursing home by tracking movement. This meant that behaviour could be monitored without the need to place a tracker on the PwD.

Holmes et al. [26] evaluated the Vigil system. Setup comprised a bed exit sensor positioned under each resident's bed sheet, and bathroom and bedroom exit monitors. Vigil alerted caregivers via a silent pager when a 'high-risk' resident exited his or her bed, bedroom, or bathroom and produced statistical norms for each resident. It was expected was that the presence of an automated sensing system would reduce the number of times that nurses would have to check residents' nocturnal status, thus decreasing the carer's burden. The results suggested that staff commitment actually increased on average 6 minutes more per person per month. There was not a significant, sustained reduction in falls and injuries in the intervention group as contrasted with the comparison group, but there was a significant difference in affective disorder, with the intervention group showing improved affect.

Franco et al. [21] conducted a feasibility study of a system for non-invasive monitoring of the usage of domestic appliances at home. Subjects were fed back results to indicate their perceived level of independence. However the study reported that there was a 
negative impression of the users due to a prolonged equipment installation period, the preponderance of cables and the thought of being monitored. Problems were also encountered such as sensors not registering electrical activity of light emitting less than 40 watts. This highlights a potential problem with night time assistance. Also it indicates that for technology to be accepted, it should be as unobtrusive as possible and not interfere with normal daily life.

Nakano et al. [42] illustrated the use of unobtrusive infra red technologies to monitor two elderly PwD. The purpose of the exercise was to study the long-term rest-activity patterns of residents in care facilities. Using an infrared sensor system $1.5 \mathrm{~m}$ above the residents' beds, their activity along with their presence or absence from their bed was recorded over a 3 month period. Conclusions indicated that the sensor system performed accurately by analysing it against video recordings of night activity during the experiment. Thus infra red sensors have potential as an ambient technology.

\subsubsection{Wandering}

Wandering is the major concern of all carers for PwD. At night time, darkness and exacerbates home hazards. Matteson et al. [38] described a behavioural study carried by nurses with expertise in dementia care. The study was split into categories of day, evening and night. Results showed subjects were less active at night, e.g. lying, sleeping and in their own rooms. The authors suggested that excessive wandering behaviour appears to be related to activities in the environment, e.g. a quiet environment leads to less agitation and therefore less wandering.

Miura et al. [40] discussed technology for tracking movements of individuals in residential care using 'tagged' slippers and piezoelectric pressure mats. The authors indicated that for safety, pressure mats can only be placed below carpets. Makimoto et al. [35] addressed wandering in PwD using tags in a long-term dementia care unit (hospital) in Seoul. Twelve consecutive days of movement data were recorded for 8 subjects, during (1) daytime (06:00-21:00hrs), evening (21:00-24:00hrs) and night time (00:00-06:00hrs). Six of the eight subjects were detected to have moved during the night-time period, showing various movement patterns. Understanding the pattern of movement at night time may improve the safety of $\mathrm{PwD}$ who are at risk of falling.

\subsubsection{Therapy}

Simulation presences therapy (SPT) was first described by Woods and Ashley [63]. They used this intervention method with $27 \mathrm{PwD}$ living in a nursing home and reported it was successful in alleviating 'problem behaviours' such as social isolation, verbal aggression or agitation. An example of night time assistive success was reported where one resident required antipsychotic medication every night for episodes of screaming. When an SPT audiotape was used for 1 hour every evening, the need for medications was eliminated.

Recreational therapy was studied by Lee et al. [33]. The study introduced gardening as a therapy for PwD to partake in with their carers. Gardening could provide a sense of 
accomplishment, create no extra care-giving workload, be easily integrated into environment; and be enjoyable for both caregivers and PwD. Whilst it did not aid sleep onset or wake-up time it had a positive effect on agitation and cognitive ability.

Van Hoof et al. [27] assessed the effects of exposure to high-intensity bluish and yellowish light on behaviour and circadian rhythmicity of institutionalised older PwD. The authors indicated that when light intervention was used a more normal circadian rhythm was established.

\subsubsection{AT Design and acceptance}

Good design of AT for PwD is important to ensure the success of feasibility studies. Orpwood et al. [44] investigated the user requirements analysis, design and evaluation of smart home solutions for PwD. The authors provided an information blueprint to develop AT geared towards the assistance of PwD.

Cahill et al. [10] evaluated the use of AT for PwD living at home in a study called "ENABLE". The focus was on 5 items; an automatic night and day calendar, a lost item locator, an automatic night lamp, a gas cooker and a picture button telephone. Results showed that the calendar, picture telephone and lost item locator were useful but carers had to repeatedly remind the PwD to use the technology. The calendar and picture phone were used after the trail, representing a successful case study. Findings show that unfamiliar items to PwD were problematic and misunderstood. Adlam et al. [2] had similar findings investigating the ENABLE project in the UK and Lithuanian.

\subsection{Day applicable to night $(\mathrm{D} \rightarrow \mathrm{N})$.}

Many studies exist to further our knowledge into the understanding of dementia and how AT can be implemented to aid the person in their environment. Day time study could be applicable for the implementation of appropriate technology into the night time environment. This category provided $68 \%$ of the papers analysed (Fig. 3).

\subsubsection{Monitoring and alerting in 'Smart Homes'}

AT is intended both for safety applications (e.g. the provision of guidance systems and messages) and to provide sensory stimulation (e.g. multi-sensory stimulation of light, music and tactile stimulation, sometimes known as "Snoezelen" [15] and ICT for social inclusion.

Arcelus et al. [6] described intelligent sensors which may be used to form a monitoring and alarm system. The sensors included magnetic switches on doors for monitoring movement from room to room, thermostats which measured room temperature, appliance temperature (e.g. oven or faucet water) or body temperature. Accelerometers measured loss of balance and falling. Radio Frequency Identification (RFID) tags were placed on commonly misplaced objects for retrieval while infrared motion sensors tracked presence and motion throughout the home. Microphone arrays were used to facilitate 
communication with the resident or to detect abnormal noises or calls for help. Grab bars were placed to aid people's transfer on and off toilets, in and out of doors and entry and exit of baths and showers. The physical pressures exerted on grab bars could, over time, be used to identify improvement or decline in strength and balance. Pressure sensitive mats were installed under bed mattresses to monitor the rest dynamics. An array of $8 * 3$ pressure sensors, measured the positioning and posture while lying down and lying to rising transitions. Identifying these changes could lead to preventing falls injuries [49].

The use of electronic noses can be used to recognize changes from normal smells to identify things from personal hygiene to burning food. These are very important aspects of night time associated care. Chen et al. [13] produced a bathroom monitoring system to provide statistical usage of bathroom appliances from showering, bathing, cleaning teeth and washing hands.

All these technologies provide a good basis for assisting people in the hours of darkness. However to date, evidence is not consistent as to the benefit. Martin et al. [36], in a Cochrane review, reported a lack of empirical evidence to support or refute the use of smart home technologies within health and social care. Indeed there is less evidence of solutions particularly tailored for the night-time period when the $\mathrm{PwD}$ and their carer are particularly vulnerable and in need of ambient assistance.

\subsubsection{Wandering}

Global Positioning Satellite (GPS) technology has been developed as a tracking tool in order to analyse movement of people both day and night. One experiment [52] tracked groups of people in 3 categories (healthy, mild cognitive impairment and persons with mild dementia) aged over 65 . Another form of tracking movements is by radio-frequency identification (RFID). Altus et al. [3] evaluated electronic monitoring. Positive results were suggested and that the device received endorsement from professionals, family caregivers, search and rescue workers, and users of the equipment. More AT can utilise the information these trackers provide [11] whilst also acting as a locator if the PwD found themselves in an unfamiliar location and needed assistance. Wild et al. [59] interviewed people aged over 65 and a family member/friend regarding acceptability of devices such as a health aid/location tracker. Results showed that more concern regarding technology was perceived from the support group than the person to be monitored. This is not a view shared by all studies but does show that many vulnerable people appreciate the need for AT.

\subsubsection{Reminiscence}

Reminiscing requires prompts aimed at stimulating feelings and memories e.g. the use of audio and visual triggers to stimulate recall [24]. The impact of reminiscing therapy as an intervention has been examined; Wang [56] demonstrated how it was valuable and beneficial to PwD although Woods et al. [62] found inconclusive evidence of the efficacy of reminiscence therapy for dementia in a Cochrane Review. However the authors noted that reminiscence therapy which required interaction using videos, pictures, archives and 
life story books, aided the therapy sessions. It has been shown that reminiscence in general, but especially life reviews are potentially effective methods for the enhancement of psychological well-being in older adults [8]. The therapeutic potential of place-based reminiscence has been proposed as an avenue in enhancing the quality of life for older people in long-term care facilities [12].

\subsubsection{Music}

Music therapy has been studied within dementia since the mid 1990's [30]. Whilst research into the reactions to music has been inconsistent, most have demonstrated a positive effect. At present there is no evidence into the use of music during the night, however one must assume it could play a vital role in the hours of darkness when cognitive ability wanes. One indicator as to why there are no night specific remediation therapy interventions may have been identified by Schnelle et al. [51]. Their study sought to address the reduction of noise and light at night, which may be attributed to the disruption of sleep. However there was resistance from staff members in the care facility.

Several reviews have illustrated the potential of music therapy for PwD although the underlying cognitive and behavioural processes are still somewhat unclear. One investigation [9] addressed the effect of music and visual therapy on the "Sundowning" effect. Results illustrated that providing music therapy during the day had a positive influence in increasing the cognitive ability of $\mathrm{PwD}$ the following morning. Another study [25] analysed the reaction either to live interactive music, passive pre-recorded music or silence for 30 minutes. Results showed that the visual image of someone playing provokes a greater emotional response. Ziv et al. [65] studied the effect of background music on behaviour in people with Alzheimer's disease. The authors noted increases in positive behaviour, showed reduction of repetitive agitated behaviour and other negative attributes such as wandering, fidgeting and showing aggression towards others. Witzke et al. [60] used music for people with Alzheimer's and reported success in reduction of aggression. Raglio et al. [46] investigated the influence of music therapy on people with moderate to severe levels of dementia. Results show increased communication in the group that received the therapy. Sixsmith et al. [53] found that music appeared to have significant positive effects for people with cognitive impairments. Many of those with Alzheimer's disease, despite aphasia and memory loss, continued to remember and sing old songs and dance to old tunes. Music is an important source of social cohesion and social contact so supporting its inclusion within and outside the household provided a degree of empowerment for PwD.

\subsubsection{Lighting for therapy and guidance}

Most lighting studies have been used to produce a positive impact on circadian rhythms. PwD are more likely to experience disjointed patterns in their sleep and wakening patterns. By trying to regulate these patterns into a fixed normal pattern of a day/night cycle, it is believed that the associated night time problems experienced and their potential hazards could be significantly decreased. Riemersma et al. [47] undertook a randomized controlled trial to determine whether the progression of cognitive and non- 
cognitive symptoms may be ameliorated by bright light and increased release of melatonin. Results showed light had a modest benefit in improving some cognitive and non-cognitive symptoms of dementia. Gammack [22] undertook a systematic review on the use of light therapy for depression. The findings stated that results were either inconclusive or inadequate for implementation. Lighting, of course, is of greater relevance at night time, as it can assist with guidance and hence reduce the potential hazards in the dark.

\subsubsection{Simulated presence and verbal instruction}

Lancioni et al. [32] reported on verbal instructions which were presented via technology in helping persons with mild or moderate Alzheimer's disease perform activities of daily living such as morning bathroom routines, table setting, coffee preparation, and dressing activities, applicable to the night time environment. The outcomes were not only positive but the technology used was also very affordable. Garland et al. [23] carried out a study into the effects of simulated family presence (conversational) and a placebo reading from a horticultural text. Results showed that simulated presence assisted in reducing both physical and verbal agitated behaviour in PwD.

\subsubsection{Mental training}

An aspect in the treatment of dementia is to help preserve the functions of the mind. The causes of these illnesses are not well understood to date but they all result in structural and chemical changes in the brain leading to the death of brain tissue [16]. Hence, dementia will eventually compromise normal brain functions. Research into AT to aid mental dexterity benefits from a better understanding of the illness; however there is initial evidence to suggest that AT can slow down the degradation of the brain's neurological functions. Chilukoti et al. [14] focused on creating an AT system to promote both physical exercise and cognitive stimulation. Research has shown that certain multi-sensory stimulants such as fiber optic lights and selective colours can be used to relax and control agitation of PwD. By incorporating a stationary training bicycle along with a Graphical User Interface, people can simultaneously participate in physical and cognitive exercises aiding mind and body.

There is also recent anecdotal evidence of the effect of brain training using video games. 'Brain exercise' products have been marketed, promising to help people stay mentally fit as they age and even help prevent dementia. However Papp et al. [45] reported that research does not support these claims as yet. In a review of studies they found no good evidence that brain training prevented or slowed down mental deterioration in healthy older adults.

\subsubsection{Technology for carers}

Carers play a pivotal role in the support for PwD. They provide valuable input into developing, maintaining and improving technology which assists and prolongs the life for PwD in their own homes. LoPresti et al. [34] reported on a cognitive aid with scheduling 
and interactive task guidance (an enhanced personal digital assistant). Care givers set/adjusted the daily activity schedule for the PwD. Wherton et al. [57] conducted two case study interviews. Study 1 involved caregivers and Occupation Therapist's; study 2 involved 8 PwD and 10 caregivers, two of which were partners. The authors highlighted the user needs for technologically assistance with the problems brought to light during in the interviews.

\section{Discussion}

At night time, PwD can experience aggression [5], restlessness and Sundowning in the forms of vocalisation and shouting, physically threatening behaviour, wandering, and overreaction to situations. The causes range from misunderstanding of time, irregular and excessive daytime sleeping, feeling frightened, frustration in being unable to comprehend situations, erosion of self-control and judgement through inhibitions and decreased awareness of rules about appropriate behaviour. The consequences equate to higher rates of falls, propensity to other accidents and dangers, sadness and depression.

The review has demonstrated AT has been applied to aid both the physical and mental capacity in terms of movement and guidance, memory, therapy as well as support for every day activates. Many issues overlap; for example running a therapy session can have a positive impact on mood as well as performance of activities for PwD during both the day and night time. Those therapy sessions can be influenced by carers providing information such as family pictures and appropriate music. Based on the literature study, it can be concluded that technology can play a pivotal role providing assistance to PwD.

Ethical issues must be considered in both design and implementation. Most of the larger projects had to receive ethical approval in order to attain the right to introduce AT into the home of PwD. Privacy is high on the ethical issue agenda. A dilemma arises when trying to draw the line between what is considered acceptable monitoring for help and when AT constitutes an invasion of privacy. Defining this boundary is crucial when trying to design AT, with special regards to wandering, a major night time problem.

In 2007 the UK Alzheimer's Society launched a policy on electronic tagging and safer walking technology to benefit PwD and their carers. These sentiments have been echoed by Help the Aged who accept that tagging could potentially allow PwD the chance to retain their freedom and help to keep them safe at the same time. As depicted in this literature study, the interest from both PwD and their carers was identified back in 2000 [3]. Some technological projects identified here had a strong support from ethical bodies $[35,47,48,59]$. Other studies have addressed the physical nature and usage of tracking devices through discussion groups [48, 52, 57]. These group discussions showed not only where key areas lay but also what types of solution were acceptable. This shows that whilst monitoring is a controversial subject for $\mathrm{PwD}$, there is acceptance that such AT can bring a real benefit to them, aid well being and keep a degree of their independence. 
Studies have identified that there can be major cognitive differences for PwD between the day and night but suggest that it is a consequence of a lack of day/night structure. More studies which encompass both the day and night as interrelating components should be undertaken.

There is a lack of studies which appear to lead to uptake of technology within homes post research. Research projects are foremost about building knowledge and consequently the focus is not on developing an actual product for long term use. Whatever the reason, given the level of research, there appears to be a major gap in the availability of AT, commercially or otherwise for PwD. This situation may improve as sensors become more unobtrusive, facilitating a truly ambient solution. Also it is likely that such technology may find a place in the "mainstream" smart home, which should decrease cost.

User acceptance from stakeholders is key. The stakeholders are: PwD, their carers, healthcare professionals, charities and support groups, the providers of technology, and the providers of social care, including government funning agencies. Hence any technology must be unobtrusive, fit for purpose, value for money, and require minimal maintenance.

\section{Recommendations}

A number of recommendations for the advancement of AT to aid PwD in the hours of darkness can be formulated using the findings of this review. These recommendations are both a statement on the quantity of night-based research and suggestive as to what will benefit PwD in the hours of darkness.

5.1 More research into the aspects and hazards of the night time environment for people with dementia.

There is a significant shortage of night time studies and many of the studies which encompass the night time are set in hospital wards or care homes. Whilst there are many different levels of dementia the risks and hazards of different living environments also need to be considered. For example, people who live at home are more self reliant and therefore perform more tasks such as cooking. Also there is a much greater contrast in the levels of supervision. Those who live at home may have no assistance available and this drastically increases the probability of problems. A wider range of night time studies which cover all levels of dementia and the location environment need to be conducted.

\subsection{Instructions and simulated presence}

An area which became apparent during the investigation was that a physical presence helped PwD in many ways. It helped to reduce confusion and aggression which was a real area of concern for people who lived at home. It helped PwD feel more reassurance and reduce confusion. It also was seen as a way to help more severe PwD perform tasks 
such as toileting, dressing and daily activities such as laying the table. AT to aid PwD either perform tasks or to help confusion without round the clock supervision could be mediated through an avatar. By recording commands, phrases or words, a system could provide round the clock assistance to PwD in the early stages of the disease by enabling them to live more independently whilst also reducing the burden on the carers.

\subsection{Time Pacing}

As identified earlier, therapy can have a major impact on the night time environment. This review includes the case for music therapy but highlighted difficulties in timing and scheduling of structured sessions. Other therapies discussed such as physical exercise or therapeutic gardening have also highlighted their effect on mood. These studies have identified the need to regulate the day/night pattern to help cognitive and emotional behaviour. Technologies such as digital TV, instructed presentations via avatar as planned activities can all help facilitate pacing. Taking this into consideration Table 3 illustrates methods, therapeutic and otherwise as an aid to introduce and help regulate pacing.

\subsection{Intervention}

Using sensing AT to provide intervention can provide assistance to PwD. For example at night, a PwD may get up to go to the toilet, but due to confusion not return to bed. This can be sensed by a technology assisted home, and a simulated presence may be used to guide the person back to bed, possibly by using lighting guidance in addition to verbal instruction. Digital TV, a familiar technology can be the enabler, and additional sensors (switches and movement detectors) can be embedded unobtrusively within the home. Where a person does not return, communication technology may be used to inform a carer, warden or healthcare professionals, as appropriate to circumstances.

\subsection{User-centred design and acceptance}

Previous studies have indicated user disappointment with many aspects of AT. This can be with installation, reliability, functionality and removal of the technology at the end of a study period. There are now many sensor devices and pervasive computing applications to Assistive technology has It is important to involve stakeholders, wherever possible, in all aspects of the research. It is also important not raise expectations and ensure solutions that are fit for purpose, and adhere to the highest ethical considerations. Thus involvement of a multidisciplinary team is a key component in such research studies.

\section{Conclusions}

This paper has addressed the use of AT for PwD in the hours of darkness. Table 4 highlights the technology discussed in this paper. What is apparent is that AT care focus is overwhelmingly biased towards day-time care. Studies have demonstrated scenarios and complications that night time care can pose. At night, physiological and sensorial 
perception is different. Added to this, ineffective lighting increases the propensity of falls and accidents accompanied by a weakened care network where less people are around to care for PwD. More research is needed into specific aspects of night time care and how AT can not only aid quality of life but possibly prolong the time PwD could live at home. There is no conclusive evidence to suggest that day time methods and technologies cannot be applicable to night time, however there is also no evidence to suggest that they can, without further consideration. For this reason we suggest a holistic approach is needed to manage both day and night time efficiently. Further night time research into the appropriate technology, its intervention and how users interact with the technology is needed. This research could yield a better understanding of problems and AT could not only enhance independence for the sufferers, but lighten the burden on their carers. 


\section{References}

[1] AccessIT: What is assistive technology, http://www.washington.edu/accessit/articles?109, accessed February 2009.

[2] T. Adlam, R. Faulkner, R. Orpwood, K. Jones, J. Macijauskiene, and A. Budraitiene, The installation and support of internationally distributed equipment for people with dementia, IEEE Transactions on Information Technology in Biomedicine. 8(3) (2004), 253-257.

[3] D.E. Altus, R.M. Mathews, P.K. Xaverius, K.K. Engelman and B.A.D. Nolan, Evaluating an electronic monitoring system for people who wander, American Journal of Alzheimer s Disease and Other Dementias, 15(2) (2000), 121.

[4] Alzheimer's Australia 2005: What is dementia?, http://www.alzheimers.org.au/upload/HS1.1.pdf, accessed February 2009.

[5] Alzheimer's Society: Dealing with aggressive behaviour, http://alzheimers.org.uk/site/scripts/documents_info.php?documentID=96, accessed February 2009.

[6] A. Arcelus, M.H. Jones, R. Goubran and F. Knoefel, Integration of smart home technologies in a health monitoring system for the elderly, Proceedings of the $21 \mathrm{st}$ International Conference on Advanced Networking and Applications Workshops/Symposia, 2 (2007), 820-825.

[7] J.C. Augusto, P. McCullagh, V. McClelland and J.A. Walkden, Enhanced healthcare provision through assisted decision-making in a smart home environment. Volume Proceedings of the 2nd Workshop on Artificial Intelligence Techniques for Ambient Intelligence - AITAmI'07, IJCAI, (2007), 27-32.

[8] E. Bohlmeijer, M. Roemer, P. Cuijpers and F. Smit, The effects of reminiscence on psychological well-being in older adults: a meta-analysis, Aging and Mental Health, 11(3) (2007), 291-300.

[9] R.A. Bruer, E. Spitzriagel and C.R. Cloninger, The temporal limits of cognitive change from music therapy in elderly persons with dementia or dementia-like cognitive impairment: A Randomized controlled trial, J. of music therapy, 44 (2007), 308-328. [10] S. Cahill, E. Begley, J.P. Faulkner and I. Hagen. It gives me a sense of independence - Findings from Ireland on the use and usefulness of assistive technology for people with dementia. Technology and Disability, - IOS Press, 2007.

[10] E. Campo and M. Chan, Detecting Abnormal Behavior by Real-Time Monitoring of Patients, Proc. AAAI Workshop Automation as Caregiver, AAAI Press, (2002), 8-12.

[12] H. Chaudhury, Quality of life and Place-Therapy, Journal of Housing for the Elderly, 17 (2003), 85-103.

[13] J.F. Chen, A.H. Kam, J.M. Zhang, N. Liu and L. Shue, Bathroom activity monitoring based on sound, Pervasive Computing, Proceedings, 3468 (2005), 47-61.

[14] N. Chilukoti, K. Early, S. Sandhu, C. Riley-Doucet and D. Debnath, Assistive technology for promoting physical and mental exercise to delay progression of cognitive degeneration in patients with dementia, 2007 Ieee Biomedical Circuits and Systems Conference, (2007), 235-238.

[15] J.C.C. Chung and C.K.Y. Lai, Snoezelen for dementia. The Cochrane Database of Systematic Reviews, 4 (2002). 
[16] Department of Health: Living well with dementia: A National Dementia Strategy: http://www.dh.gov.uk/en/Publicationsandstatistics/Publications/PublicationsPolicyAndG uidance/DH_094058, accessed February (2009).

[17] DofH2004: Improving Chronic Disease Management, Department of Health, http://www.dh.gov.uk, accessed February 2009.

[18] FAST: Definition of the term 'Assistive Technology', http://www.fastuk.org/about/definitionofat.php, accessed February 2009.

[19] C.P. Ferri, M. Prince, C. Brayne, et al. Global prevalence of dementia: a Delphi consensus study, Lancet 366: (2005), 2112-17.

[20] F.M. Folstein, S.E. Folstein, and P.R. McHugh, Mini-mental state: A practical method for grading the cognitive state of patients for the clinician. Journal of Psychiatric Research, 12 (1975), 189-198.

[21] G.C. Franco, F. Gallay, M. Berenguer, C. Mourrain and P. Couturier, Non-invasive monitoring of the activities of daily living of elderly people at home - a pilot study of the usage of domestic appliances, Journal of telemedicine and telecare, 14(5) (2008), 231235.

[22] J.K. Gammack, Light therapy for insomnia in older adults, Clinics in geriatric medicine, 24(1) (2008), 139+.

[23] K. Garland, E. Beer, B. Eppingstall and D.W. O'Connor, A comparison of two treatments of agitated behavior in nursing home residents with dementia: Simulated family presence and preferred music, American Journal of Geriatric Psychiatry, 15(6) (2007), 514-521.

[24] F. Gibson, The Past in the Present: Using reminiscence in health and social care, Baltimore: Health Professions Press, 2004.

[25] C. Holmes, A. Knights, C. Dean, S. Hodkinson and V. Hopkins, Keep music live: music and the alleviation of apathy in dementia subjects, International Psychogeriatrics, 18(4) (2006), 623-630.

[26] D. Holmes, J.A. Teresi, M. Ramirez, J. Ellis, J. Eimicke, J. Kong, L. Orzechowska and S. Silver, An evaluation of a monitoring system intervention: falls, injuries, and affect in nursing homes, Clinical Nursing Research 16 (2007), 317-335.

[27] J. van Hoof, M.P.J. Aarts, C.G. Rense and A.M.C. Schoutens, Ambient bright light in dementia: effects on behaviour and circadian rhythmicity, Building and Environment; 44(1) (2009), 146-155.

[28] T. Hori, Y. Nishida, and H. Aizawa, Sensor network for supporting elderly care home, IEEE Proceeding of Sensors, 2 (2004), 575 - 578.

[29] ILO 2004: Employment strategy-EMP/TRENDS-World Employment Report 2004/2005. http://www.ilo.org/public/english/employment/strat/download/wr04c1en.pdf, accessed February 2009.

[30] S. M. Koger, K. Chapin, \& M. Bortons, Is Music therapy an effective intervention for dementia? A meta-analytic review of literature, Journal of Music Therapy, 36 (1999), $2-15$.

[3`] L. Kurlowicz, and M. Wallace, The Mini-Mental State Examination (MMSE).

Journal of Gerontological Nursing, 25(5) (1999), 8-9.

[32] G.E. Lancioni, M.L. La Martire, N.N. Singh, M.F. O'Reilly, J. Sigafoos, K. Pinto and M.G. Minervini, Persons With Mild or Moderate Alzheimer's Disease Managing 
Daily Activities via Verbal Instruction Technology, American Journal of Alzheimers Disease and Other Dementias, 23(6) (2008), 552-562.

[33] Y. Lee and S. Kim, Effects of indoor gardening on sleep, agitation, and cognition in dementia patients--a pilot study, International Journal of Geriatric Psychiatry, 23(5) (2006).

[34] E.F. LoPresti, R.C. Simpson, N. Kirsch, D. Schreckenghost and S. Hayashi, Distributed cognitive aid with scheduling and interactive task guidance, Journal of Rehabilitation Research and Development,45(4) (2008), 505-521.

[35] K. Makimoto, E.A. Lee, Y. Kang, M. Yamakawa, N. Ashida and K.R. Shin, Temporal patterns of movements in institutionalized elderly with dementia during 12 consecutive days of observation in Seoul, Korea, American Journal of Alzheimers Disease and Other Dementias, 23(2) (2008), 200-206.

[36] S. Martin, G. Kelly, W.G. Kernohan, B. McCreight and C. Nugent, Smart home technologies for health and social care support, Cochrane Database of Systematic Reviews, 4 (2008).

[37] S.M. McCurry, L.E. Gibbons, R.G. Logsdon, M.V. Vitiello and L. Teri, Nighttime insomnia treatment and education for Alzheimer's disease: a randomized, controlled trial, Journal of the American Geriatrics Society, 53 (2005), 793-802.

[38] M.A. Matteson and A. Linton, Wandering behaviors in institutionalized persons with dementia. J. Gerontol. Nurs. (1996), 39-46.

[39] Merck: Dementia: Delirium and Dementia, http://www.merck.com/mmpe/sec16/ch213/ch213c.html\#tb213_03, accessed February 2009.

[40] M. Miura, S. Ito, R. Takatsuka and S. Kunifuji, Aware group home enhanced by RFID technology, Proceedings of KES'08, 5178 (2008), 847-854.

[41] R.A. Murden, T.D. McRae, S. Kaner, and M.E. Bucknam, Mini-Mental State Exam scores vary with education in Blacks and Whites, J. Am. Geriatr. Soc., 39 (1999), 149155.

[42] T. Nakano, E. Koyama, T. Nakamura, T. Ito, K. Tamura and M. Yaginuma, Use of an infrared sensor system to take longterm bedside measurements of rest-activity patterns in the elderly with dementia, Psychiatry \& Clinical Neurosciences, 56(3) (2002), 287-8. [43] NIHPS2004: NI Home Prevention Strategy 2004-2009, http://www.rospa.com/ni/info/hap_strat_04.pdf, accessed February 2009.

[44] R. Orpwood, C. Gibbs, T. Adlam, R. Faulkner and D. Meegahawatte, The design of smart homes for people with dementia user-interface aspects, Universal Access in the Information Society, 4(2) (2005), 156-164.

[45] K.V. Papp, S.J. Walsh and P.J. Snyder, Immediate and delayed effects of cognitive interventions in healthy elderly: A review of current literature and future directions, Alzheimers and Dementia, 5(1) (2009), 50-60.

[46] A. Raglio, G. Bellelli, D. Traficante, M. Gianotti, M.C. Ubezio, D. Villani and M. Trabucchi, Efficacy of music therapy in the treatment of behavioral and psychiatric symptoms of dementia, Alzheimer Disease and Associated Disorders,22(2) (2008), 158162.

[47] R.F. Riemersma-van der Lek, D.F. Swaab, J. Twisk, E.M. Hol, W.J.G. Hoogendijk and E.J.W Van Someren, Effect of bright light and melatonin on cognitive and noncognitive function in elderly residents of group care facilities - A randomized 
controlled trial, Jama-Journal of the American Medical Association, 299(22) (2008), 2642-2655.

[48] L. Robinson, D. Hutchings, H. O. Dickinson, L. Corner, F. Beyer, T. Finch, J. Hughes, A. Vanoli1, C. Ballard and J. Bond, Effectiveness and acceptability of nonpharmacological interventions to reduce wandering in dementia: a systematic review, International Journal of Geriatric Psychiatry, 22, (2006).

[49] M. A. Rowe and N. Fehrenbach, Injuries sustained by community-dwelling individuals with dementia. Clinical Nursing Research, 13(2) (2004), 98-110.

[50] Y. Schikhof and I. Mulder, Under Watch and Ward at Night: Design and Evaluation of a Remote Monitoring System for Dementia Care, Hci and Usability for Education and Work, Proceedings, 5298 (2008), 475-486.

[51] J.F. Schnelle, C.A. Alessi, N.R. Al-Samarrai, R.D. Fricker and J.G. Ouslander, The nursing home at night: Effects of an intervention on noise, light and sleep, Journal of the American Geriatrics Society 47 (1999), 430-438.

[52] N. Shoval, G.K. Auslander, T. Freytag, R. Landau, F. Oswald, U. Seidl, H. Wahl, S. Werner and J. Heinik, The use of advanced tracking technologies for the analysis of mobility in Alzheimer's disease and related cognitive diseases, BMC Geriatrics, 8 (2008), 7.

[53] A. Sixsmith and G. Gibson, Music and the wellbeing of people with dementia, Ageing and Society, 27 (2007), 127-145.

[54] Tong Lien Doan Lao Dong Viet Nam:

http://www.congdoanvn.org.vn/english/details.asp?l=1\&c=268\&c2=268\&m=283, accessed February 2009

[55] J.M. Torrington and P.R. Tregenza, Lighting for people with dementia, Lighting

Research and Technology, 39(1) (2007), 81-97.

[56] J.J. Wang, Group reminiscence therapy for cognitive and affective function of demented elderly in Taiwan, International Journal of Geriatric Psychiatry, 22(12) (2007), 1235-1240.

[57] J.P. Wherton and A.F. Monk, Technological opportunities for supporting people with dementia who are living at home, International. Journal. of Human-Computer Studies, 66(8) (2008), 571-586.

[58] WHO2005: The world is fast ageing - have we noticed?

http://www.who.int/ageing/en, accessed February 2009.

[59] K. Wild, L. Boise, J. Lundell and A. Foucek, Unobtrusive in-home monitoring of cognitive and physical health: Reactions and perceptions of older adults, Journal of Applied Gerontology, 27(2) (2008), 181-200.

[60] J. Witzke, R.A. Rhone, D. Backhaus and N.A. Shaver, How sweet the sound Research evidence for the use of music in Alzheimer's dementia, Journal of gerontological nursing, 34(10) (2008), 45-52.

[61] A. Wood, G. Virone, T. Doan, Q. Cao, L. Selavo, Y. Wu, L. Fang, Z. He, S. Lin and J. Stankovic, ALARM-NET: Wireless Sensor Networks for Assisted-Living and Residential Monitoring, Technical Report CS-2006-11, Dept. of Computer Science, Univ. of Virginia, 2006.

[62] B. Woods, A. Spector, C. Jones, M. Orrell and S. Davies, Reminiscence therapy for dementia, Cochrane Database Systematic Review, 2 (2005), CD001120. 
[63] P. Woods and J. Ashley, Simulated presence therapy: Using selected memories to manage problem behaviors in Alzheimer's disease patients, Geriatric Nursing, 16(1) (1995), 9-14.

[64] S.H. Zarit, and J. M. Zarit, Mental disorders in older adults: Fundamentals of assessment and treatment. The Guilford Press: New York, 1998.

[65] N. Ziv, A. Granot, S. Hai, A. Dassa and I. Haimov, The effect of background stimulative music on Behavior in Alzheimer's patients, Journal of music therapy,44 (2007), 329-343. 
Table 1: Paper Details and Classification Based on Abstracts

\begin{tabular}{|c|c|c|c|c|}
\hline Category & Area & Includes & $\begin{array}{l}\text { First Selection } \\
(\mathbf{N} 1=131)\end{array}$ & $\begin{array}{l}\text { Final Selection } \\
(\mathrm{N} 2=54)\end{array}$ \\
\hline \multirow{4}{*}{ Technology for PwD } & Smart Home & $\begin{array}{l}\text { PIR, door, RFID, automatic devices, } \\
\text { failsafe devices. }\end{array}$ & 28 & 11 \\
\hline & Tracking \& Guidance & RFID, GPS, PIR, Lighting & 15 & 6 \\
\hline & Communication Devices & iTV, touch screen, telephone & 6 & 5 \\
\hline & Mental Stimulation & Brain training, games & 3 & 2 \\
\hline \multirow{2}{*}{$\begin{array}{l}\text { Technology for } \\
\text { Carers }\end{array}$} & Devices & Communications devices, trackers & 2 & 1 \\
\hline & Service provision & Task scheduling, guidance & 1 & \\
\hline \multirow{2}{*}{ Background work } & PwD Assessment & $\begin{array}{l}\text { MMSE, Cohen-Mansfield Agitation } \\
\text { Inventory (CMAI), interviews }\end{array}$ & 1 & \\
\hline & Ethics and privacy & Board approval, interviews & 1 & \\
\hline \multirow{3}{*}{ Reviews } & Systematic & use of technology, design, sleep & 9 & 5 \\
\hline & Technological & $\begin{array}{l}\text { Communications, warning, detection, } \\
\text { failsafe devices }\end{array}$ & 8 & 5 \\
\hline & Symptomatic & $\begin{array}{l}\text { Aggression, Anxiety, Confusion, } \\
\text { Cognation. }\end{array}$ & 13 & 4 \\
\hline \multirow{5}{*}{ Therapy for PwD } & Lighting & $\begin{array}{l}\text { Light boxes, ceiling lights, natural } \\
\text { lighting for stimulation }\end{array}$ & 12 & 2 \\
\hline & Music & Listening, playing, watching & 16 & 6 \\
\hline & Simulated Presence & Avatar, vocal instructions/reassurance & 3 & 1 \\
\hline & Reminiscence & Video, Photos, music & 6 & 3 \\
\hline & Physical & Walking, exercise, gardening & 2 & 1 \\
\hline \multirow{3}{*}{ Miscellaneous } & $\begin{array}{l}\text { Timing of the daily } \\
\text { activities }\end{array}$ & Sleep patterns (day/night/sundowning) & 3 & \\
\hline & Behavioural & Restlessness, aggression & 1 & 1 \\
\hline & Education & Talks, information handouts & 1 & 1 \\
\hline
\end{tabular}


Detecting abnormal behaviour by real-time monitoring of patients [11]

\section{$\mathrm{N}$}

Under Watch and Ward at Night: Design and Evaluation of a Remote Monitoring

System for Dementia Care [50]

Lighting for people with dementia [55]

$\mathrm{N}$

$\checkmark \quad \checkmark \quad \checkmark$

$\checkmark$

Nighttime insomnia treatment and education for Alzheimer's disease: a

randomized, controlled trial [37]

"It gives me a sense of independence" - findings from Ireland on the use and usefulness of assistive technology for people with dementia. [10]

Wandering behaviors in institutionalized persons with dementia. [38]

[38] N/D

Temporal patterns of movements in institutionalized elderly with dementia during

12 consecutive days of observation in Seoul, Korea [35]

ALARM-NET: Wireless Sensor Networks for Assisted-Living and Residential

Monitoring [61]

Non-invasive monitoring of the activities of daily living of elderly people at home

- a pilot study of the usage of domestic appliances [21]

Simulated presence therapy: Using selected memories to manage problem

behaviors in Alzheimer's disease patients [63]

An evaluation of a monitoring system intervention: falls, injuries, and affect in

nursing homes. [25]

Aware group home enhanced by RFID technology [40]

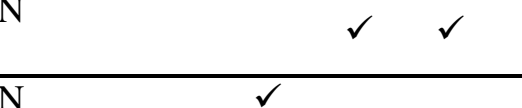

\begin{tabular}{lllll} 
& & & $\checkmark$ & $\checkmark$ \\
\hline & & $\checkmark$ & & $\checkmark$
\end{tabular}

N/D

N/D

$\checkmark$

$\checkmark$

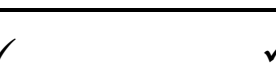

$\checkmark$

$\checkmark \quad \checkmark \quad \checkmark$

$\begin{array}{llllllllllll} & \checkmark & \checkmark & \checkmark & \checkmark & \checkmark\end{array}$

N/D

N/D

Use of an infrared sensor system to take long-term bedside activity patterns in the elderly with dementia [42] 
Effects of indoor gardening on sleep, agitation, and cognition in dementia

patients--a pilot study [33]

Ambient bright light in dementia: Effects on behaviour and circadian rhythmicity $\mathrm{N} / \mathrm{D}$

[27]

The design of smart homes for people with dementia-user-interface aspects [44] N/D

The installation and support of internationally distributed equipment for people $\quad$ N/D

with dementia [2]

Sensor network for supporting elderly care home [28]

Unobtrusive in-home monitoring of cognitive and physical health: Reactions and $\mathrm{D} \Rightarrow \mathrm{N}$

perceptions of older adults [59]

The temporal limits of cognitive change from music therapy in elderly persons

with dementia or dementia-like cognitive impairment: A Randomized controlled

trial [9]

Integration of Smart Home Technologies in a Health Monitoring System for the

Elderly [6]

Bathroom Activity Monitoring Based on Sound [13]

The use of advanced tracking technologies for the analysis of mobility in

Alzheimer's disease and related cognitive diseases [52]

Evaluating an electronic monitoring system for people who wander [3]

Reminiscence therapy for dementia [62]

Persons With Mild or Moderate Alzheimer's Disease Managing Daily Activities

via Verbal Instruction Technology [32]

Efficacy of music therapy in the treatment of behavioral and psychiatric

symptoms of dementia [46]

Light therapy for insomnia in older adults [22]

Music and the wellbeing of people with dementia [53]

Smart home technologies for health and social care support [36]

Keep music live: music and the alleviation of apathy in dementia subjects [25]

Technological opportunities for supporting people with dementia who are living at home [57]

The effect of background stimulative music on Behavior in Alzheimer's patients

[65]

$\mathrm{N} / \mathrm{D}$

$\checkmark$

D

\begin{tabular}{ll} 
& $\checkmark$ \\
\hline & $\checkmark$
\end{tabular}

$\mathrm{D} \Rightarrow \mathrm{N} \quad \checkmark$

$\mathrm{D} \Rightarrow \mathrm{N}$

$\mathrm{D} \Rightarrow \mathrm{N}$

$\mathrm{D} \Rightarrow \mathrm{N}$

\begin{tabular}{lcccccc}
$\mathrm{D} \Rightarrow \mathrm{N}$ & $\checkmark$ & $\checkmark$ & $\checkmark$ & & & $\checkmark$ \\
$\mathrm{D} \Rightarrow \mathrm{N}$ & $\checkmark$ & $\checkmark$ & $\checkmark$ & $\checkmark$ & $\checkmark$ & $\checkmark$ \\
& & & & & & \\
\hline $\mathrm{D} \Rightarrow \mathrm{N}$ & $\checkmark$ & $\checkmark$ & $\checkmark$ & & $\checkmark$ & $\checkmark$
\end{tabular}

$\mathrm{D} \Rightarrow \mathrm{N}$

$\mathrm{D} \Rightarrow \mathrm{N}$

$\mathrm{D} \Rightarrow \mathrm{N}$

$\mathrm{D} \Rightarrow \mathrm{N}$

$\mathrm{D} \Rightarrow \mathrm{N}$

$\mathrm{D} \Rightarrow \mathrm{N}$

$\mathrm{D} \Rightarrow \mathrm{N}$

$\mathrm{D} \Rightarrow \mathrm{N}$

$\mathrm{D} \Rightarrow \mathrm{N}$

\begin{tabular}{|c|c|c|c|c|c|c|c|}
\hline & $\checkmark$ & $\checkmark$ & $\checkmark$ & & $\checkmark$ & & $\bar{\checkmark}$ \\
\hline $\bar{\checkmark}$ & & $\checkmark$ & & $\checkmark$ & & & \\
\hline & $\checkmark$ & $\checkmark$ & & $\checkmark$ & & $\checkmark$ & $\checkmark$ \\
\hline$\checkmark$ & & & $\checkmark$ & $\checkmark$ & & & \\
\hline $\bar{\checkmark}$ & & & & $\checkmark$ & & & \\
\hline & $\checkmark$ & & & $\checkmark$ & $\checkmark$ & $\checkmark$ & $\sqrt{ }$ \\
\hline$\checkmark$ & & $\checkmark$ & $\checkmark$ & $\checkmark$ & $\checkmark$ & & \\
\hline & $\checkmark$ & & & $\checkmark$ & $\checkmark$ & $\checkmark$ & ( \\
\hline & $\checkmark$ & $\checkmark$ & & & $\checkmark$ & $\checkmark$ & $\checkmark$ \\
\hline & $\checkmark$ & & $\checkmark$ & $\checkmark$ & $\checkmark$ & & $\checkmark$ \\
\hline
\end{tabular}




\begin{tabular}{|c|c|c|c|c|c|c|c|c|c|}
\hline Distributed cognitive aid with scheduling and interactive task guidance [34] & $\mathrm{D} \Rightarrow \mathrm{N}$ & $\checkmark$ & & & & $\checkmark$ & $\checkmark$ & & \\
\hline $\begin{array}{l}\text { How sweet the sound - Research evidence for the use of music in Alzheimer's } \\
\text { dementia [60] }\end{array}$ & $\mathrm{D} \Rightarrow \mathrm{N}$ & & $\checkmark$ & & & $\checkmark$ & $\checkmark$ & & \\
\hline $\begin{array}{l}\text { Effect of bright light and melatonin on cognitive and noncognitive function in } \\
\text { elderly residents of group care facilities - A randomized controlled trial [47] }\end{array}$ & $\mathrm{D} \Rightarrow \mathrm{N}$ & & $\checkmark$ & & & $\checkmark$ & $\checkmark$ & $\checkmark$ & $\checkmark$ \\
\hline $\begin{array}{l}\text { Effectiveness and acceptability of non-pharmacological interventions to reduce } \\
\text { wandering in dementia: a systematic review [48] }\end{array}$ & $\mathrm{D} \Rightarrow \mathrm{N}$ & $\checkmark$ & & & $\checkmark$ & $\checkmark$ & & $\checkmark$ & \\
\hline $\begin{array}{l}\text { Assistive technology for promoting physical and mental exercise to delay } \\
\text { progression of cognitive degeneration in patients with dementia [14] }\end{array}$ & $\mathrm{D} \Rightarrow \mathrm{N}$ & & $\checkmark$ & $\checkmark$ & $\checkmark$ & & $\checkmark$ & & $\checkmark$ \\
\hline $\begin{array}{l}\text { A. Carmichael, M. Rice, S. Lindsay, and P. Olivier, iTV as a platform for rich } \\
\text { multimedia reminders for people with dementia, Changing Television } \\
\text { Environments, Proceedings, } \mathbf{5 0 6 6} \text { (2008), 308-317. }\end{array}$ & $\mathrm{D} \Rightarrow \mathrm{N}$ & & $\checkmark$ & $\checkmark$ & & $\checkmark$ & & & \\
\hline $\begin{array}{l}\text { R. Orpwood, J. Chadd, D. Howcroft, A. Sixsmith, J. Torrington, G. Gibson and } \\
\text { G. Chalfont, User-led design of technology to improve quality of life for people } \\
\text { with dementia, Designing Inclusive Futures, (2008), 185-195. }\end{array}$ & $\mathrm{D} \Rightarrow \mathrm{N}$ & $\checkmark$ & & $\checkmark$ & $\checkmark$ & & $\checkmark$ & & \\
\hline $\begin{array}{l}\text { C. Nugent, F. Moelaert, R. Davies, M. Donnelly, S. Savenstedt, F. Meiland, R.M. } \\
\text { Droes, M. Hettinga, D. Craig, M. Mulvenna, and J.E. Bengstsson, Evaluation of } \\
\text { mobile and home based cognitive prosthetics, Smart Homes and Health } \\
\text { Telematics, } \mathbf{5 1 2 0} \text { (2008), 18-25. }\end{array}$ & $\mathrm{D} \Rightarrow \mathrm{N}$ & $\checkmark$ & & $\checkmark$ & & & $\checkmark$ & & $\checkmark$ \\
\hline $\begin{array}{l}\text { T. Hope, J. Keene, R.H. McShane, C.G. Fairburn, K. Gedling and R. Jacoby, } \\
\text { Wandering in dementia: A longitudinal study, International Psychogeriatrics, } \\
\mathbf{1 3 ( 2 )}(2001), 137-147 .\end{array}$ & $\mathrm{D} \Rightarrow \mathrm{N}$ & $\checkmark$ & & & & & $\checkmark$ & & \\
\hline $\begin{array}{l}\text { C. Siders, A. Nelson, L.M. Brown, I. Joseph, D. Algase, E. Beattie and S. } \\
\text { Verbosky-Cadena, Evidence for implementing nonpharmacological interventions } \\
\text { for wandering. Rehabil Nurs, 29(6) (2004), 195-206. }\end{array}$ & $\mathrm{D} \Rightarrow N$ & $\checkmark$ & & & $\checkmark$ & & & & \\
\hline $\begin{array}{l}\text { B. Schmitt and L. Frolich, Creative therapy options for patients with dementia - A } \\
\text { systematic review. Fortschritte Der Neurologie Psychiatrie, 75(12) (2007), 699- } \\
707 .\end{array}$ & $\mathrm{D} \Rightarrow \mathrm{N}$ & $\checkmark$ & & & & $\checkmark$ & & & \\
\hline $\begin{array}{l}\text { S.C. Gardstrom, Music Therapy As Noninvasive Treatment: Who Says? Nordic } \\
\text { Journal of Music Therapy, 17(2) (2008), 142-154. }\end{array}$ & $\mathrm{D} \Rightarrow \mathrm{N}$ & $\checkmark$ & & & & $\checkmark$ & $\checkmark$ & & \\
\hline $\begin{array}{l}\text { A. Utsumi, S. Kawato and S. Abe, Attention monitoring based on temporal } \\
\text { signal-behavior stuructures. Lecture Notes in Computer Science, } \mathbf{3 7 6 6} \text { (2005), } \\
100-109\end{array}$ & $\mathrm{D} \Rightarrow \mathrm{N}$ & & $\checkmark$ & $\checkmark$ & & & & & $\checkmark$ \\
\hline
\end{tabular}


M. Wu, R.M. Baecker, and B. Richards, Designing a Cognitive Aid for and with

$\mathrm{D} \Rightarrow \mathrm{N}$

People who have Anterograde Amnesis, Lazar, J. (Ed.), Universal Usability,

(2007), 317-356.

Casas, A. Marco, J.L. Falcó, H.J. Gracia and J.I. Artigas, DALMA - Location

Aware Alarm System for People with Disabilities, Lecture Notes in Computer

Science, 4041 (2006), 744-751

B. Winkler, An Implementation of an Ultrasonic Indoor Tracking System

Supporting the OSGi

Architecture of the ICTA Lab, Master's thesis, University of Florida, (2002).

B. Gyselinckx, R. Vullers, C. V. Hoof, J. Ryckaert, R. F. Yazicioglu, P. Fiorini,

and V. Leonov, Human++: Emerging technology for body area networks, Very

Large Scale Integration, 2006 IFIP International Conference, (2006), 175-180.

N. Kuwahars, S. Abe, K. Yasuda and K. Kuwabara, Networked reminiscence

therapy for individuals with dementia by using photo and video sharing,

Proceedings ASSETS 2006,

(2006), 125-132.

N. Alm and A. Newell, Creating innovative partnerships with users in developing

assistive technology, Computers Helping People with Special Needs,

Proceedings, $\mathbf{5 1 0 5}$ (2008), 130-137.

M. Irish, C.J. Cunningham, J.B. Walsh, D. Coakley, B.A. Lawlor, I.H. Robertson

and R.F. Coen, Investigating the enhancing effect of music on autobiographical

memory in mild Alzheimer's disease, Dementia and geriatric cognitive disorders, 22(1) (2006), 108-120.

B.K. Hensel, D. Parker-Oliver and G. Demiris, Videophone communication

between residents and family: A case study, Journal of the American Medical

$\mathrm{D} \Rightarrow \mathrm{N}$

$\Rightarrow \mathrm{N}$

$\mathrm{D} \Rightarrow \mathrm{N}$

(1)

$+1$

$\checkmark \quad \checkmark \quad \checkmark \quad \checkmark \quad \checkmark$

$\mathrm{D} \Rightarrow \mathrm{N} \quad \checkmark \quad \checkmark \quad \checkmark$

$\mathrm{D} \Rightarrow \mathrm{N}$

Directors Association, 8(2) (2007), 123-127.

M. Ohara, A. Utsumi, H. Yamazoe, S. Abe and N. Katayama, Attention

Monitoring for Music Contents Based on Analysis of Signal-Behavior Structures,

Lecture Notes in Computer Science, 4843 (2007), 292-302

$\mathrm{D} \Rightarrow \mathrm{N}$

$\mathrm{D} \Rightarrow \mathrm{N}$

$\mathrm{D} \Rightarrow \mathrm{N}$

$\mathrm{D} \Rightarrow \mathrm{N}$

$\mathrm{D}\lrcorner \mathrm{N}$

$\checkmark$

$\checkmark \checkmark$

$\checkmark$ 
Table 3: AT for Activities to Promote Time of Day Pacing

\begin{tabular}{lll}
\hline \hline Activity & $\begin{array}{l}\text { Possible } \\
\text { Assistive } \\
\text { Technology }\end{array}$ & Time of day \\
\hline \hline Music Therapy & $\begin{array}{l}\text { Digital TV, } \\
\text { personalised } \\
\text { music library }\end{array}$ & $\begin{array}{l}\text { Planned session times during } \\
\text { the day. }\end{array}$ \\
\hline Reminiscing & $\begin{array}{l}\text { Digital TV, } \\
\text { personalised } \\
\text { photo and music } \\
\text { library }\end{array}$ & $\begin{array}{l}\text { Planned session times during } \\
\text { the day. }\end{array}$ \\
\hline $\begin{array}{l}\text { Simulated } \\
\text { Presence and }\end{array}$ & $\begin{array}{l}\text { Digital TV, } \\
\text { Avatar, PIR's, } \\
\text { Rerbal Instruction }\end{array}$ & $\begin{array}{l}\text { Non specific, some planned, } \\
\text { some reactive to PwD }\end{array}$ \\
\hline Active therapy & $\begin{array}{l}\text { Keyboards, } \\
\text { touchpad's, } \\
\text { activity planner }\end{array}$ & $\begin{array}{l}\text { Planned session times during } \\
\text { the day. }\end{array}$ \\
\hline $\begin{array}{l}\text { Vocalization and } \\
\text { restlessness during } \\
\text { night }\end{array}$ & $\begin{array}{l}\text { Digital TV, } \\
\text { PIR's, pressure } \\
\text { sensors, lighting } \\
\text { and music }\end{array}$ & Reactive to PwD \\
\hline \hline
\end{tabular}


Table 4: Technology discussed in This Paper

\begin{tabular}{|c|c|c|c|}
\hline Technology & About & Used for & Area \\
\hline Accelerometer & $\begin{array}{l}\text { Measure speed and } \\
\text { directional movement }\end{array}$ & $\begin{array}{l}\text { Detecting } \\
\text { loss/deterioration } \\
\text { in balance and } \\
\text { falls }\end{array}$ & Movement \\
\hline Avatar & $\begin{array}{l}\text { A human like } \\
\text { communication/interaction } \\
\text { on a PC }\end{array}$ & $\begin{array}{l}\text { Guidance, advice } \\
\text { and } \\
\text { communication }\end{array}$ & $\begin{array}{l}\text { Communication / } \\
\text { therapy }\end{array}$ \\
\hline $\begin{array}{l}\text { Bed Occupancy } \\
\text { sensors }\end{array}$ & $\begin{array}{l}\text { Measures presence, } \\
\text { movement and pressure }\end{array}$ & $\begin{array}{l}\text { Analysing } \\
\text { sleeping quality } \\
\text { and patterns } \\
\end{array}$ & $\begin{array}{l}\text { Monitoring/ } \\
\text { Movement }\end{array}$ \\
\hline Camera & $\begin{array}{l}\text { Transmit visual images } \\
\text { from one place to another }\end{array}$ & $\begin{array}{l}\text { For visual } \\
\text { communication } \\
\text { such as therapy }\end{array}$ & $\begin{array}{l}\text { Communication / } \\
\text { therapy }\end{array}$ \\
\hline Coloured light & Colour emitted from lights & Circadian rhythms & Sleep \\
\hline $\begin{array}{l}\text { Electrical pattern } \\
\text { of usage }\end{array}$ & Measure currant & $\begin{array}{l}\text { Monitoring } \\
\text { appliances }\end{array}$ & Monitoring \\
\hline Fibre-optic & Type of light & Circadian rhythms & Sleep \\
\hline $\begin{array}{l}\text { Global } \\
\text { Positioning } \\
\text { Satellite (GPS) } \\
\end{array}$ & Satellite picks up location & $\begin{array}{l}\text { Tracking and } \\
\text { guidance }\end{array}$ & $\begin{array}{l}\text { Monitoring/ } \\
\text { Movement }\end{array}$ \\
\hline $\begin{array}{l}\text { Magnetic } \\
\text { switches/exit } \\
\text { sensors }\end{array}$ & Used on doors & $\begin{array}{l}\text { Tracking } \\
\text { movement from } \\
\text { room to room }\end{array}$ & Movement \\
\hline Microphone & Pick up audio sounds & $\begin{array}{l}\text { For audio } \\
\text { communication or } \\
\text { detection of } \\
\text { appliance noises or } \\
\text { calls for help }\end{array}$ & $\begin{array}{l}\text { Communication / } \\
\text { therapy / Health } \\
\text { aid }\end{array}$ \\
\hline $\begin{array}{l}\text { Passive InfraRed } \\
\text { sensor (PIR) }\end{array}$ & Detects movements & $\begin{array}{l}\text { Detecting } \\
\text { movement }\end{array}$ & Movement \\
\hline Picture & Family, friends, places & Reminiscence & Cognitive therapy \\
\hline Picture telephone & $\begin{array}{l}\text { Pictures instead of } \\
\text { numbers. }\end{array}$ & $\begin{array}{l}\text { One touch dial the } \\
\text { person the picture } \\
\text { relates to. }\end{array}$ & Communication \\
\hline $\begin{array}{l}\text { Piezoelectric } \\
\text { pressure mats }\end{array}$ & $\begin{array}{l}\text { Mats with a pressure } \\
\text { sensor to detect presence }\end{array}$ & $\begin{array}{l}\text { Detecting } \\
\text { movement }\end{array}$ & $\begin{array}{l}\text { Monitoring/ } \\
\text { Movement }\end{array}$ \\
\hline $\begin{array}{l}\text { Radio Frequency } \\
\text { Identification } \\
\text { (RFID) } \\
\end{array}$ & A traceable signal & $\begin{array}{l}\text { Tracking local } \\
\text { movement }\end{array}$ & $\begin{array}{l}\text { Monitoring/ } \\
\text { Movement }\end{array}$ \\
\hline $\begin{array}{l}\text { Simulated } \\
\text { Presence Therapy } \\
\text { (SPT) }\end{array}$ & $\begin{array}{l}\text { Pre-recorded } \\
\text { sentences/text }\end{array}$ & $\begin{array}{l}\text { Calming confusion } \\
\text { and } \\
\text { communication }\end{array}$ & $\begin{array}{l}\text { Communication / } \\
\text { therapy }\end{array}$ \\
\hline
\end{tabular}




\begin{tabular}{llll}
\hline Thermostats & Measures temperature & $\begin{array}{l}\text { Detecting changes } \\
\text { in room } \\
\text { temperature }\end{array}$ & Monitoring \\
\hline $\begin{array}{l}\text { Ultrasonic } \\
\text { transducer }\end{array}$ & Pulse detects movement & $\begin{array}{l}\text { Detecting } \\
\text { movement }\end{array}$ & Monitoring \\
\hline $\begin{array}{l}\text { Videos and games } \\
\text { console }\end{array}$ & Brain training/exercising & $\begin{array}{l}\text { Reduce cognitive } \\
\text { deterioration }\end{array}$ & Cognitive therapy \\
\hline \hline
\end{tabular}




\begin{tabular}{|c|c|}
\hline $\begin{array}{l}\text { Search 1: } \\
\text { "Dementia" AND "Night' } \\
\text { OR "Technology" OR "G } \\
\text { "detection" OR "therapy" }\end{array}$ & $\begin{array}{l}\text { OR "Night time" OR "Nocturnal" AND "Home" OR "Light" } \\
\text { dance" OR "Behaviour" OR "Mood" OR "Life signs" OR } \\
\text { R "assisted" OR "living" }\end{array}$ \\
\hline$\frac{\text { Search 2: }}{\text { "Dementia" AND "Sleep" }}$ & AND "Patterns" OR "Mood" OR “Technology" \\
\hline $\begin{array}{l}\text { Search 3: } \\
\text { "Dementia" AND "Techn } \\
\text { Signs" OR "Guidance" O } \\
\text { "Detection" OR "therapy" }\end{array}$ & $\begin{array}{l}\text { ogy" AND “Home" OR "Night" OR "Software" OR "Life } \\
\text { "Safety" OR "Bluetooth" OR "Wireless" OR "Motion" OR } \\
\text { OR “assisted" OR "living" }\end{array}$ \\
\hline $\begin{array}{l}\text { Search 4: } \\
\text { "Dementia" AND "Morni } \\
\text { "living" }\end{array}$ & " AND "Behaviour" OR "Waking” OR “assisted" OR \\
\hline $\begin{array}{l}\text { Search 5: } \\
\text { "Dementia" AND "Thera, } \\
\text { "aggression" OR "anger" } \\
\text { "living" }\end{array}$ & $\begin{array}{l}\text { ” AND “music" OR “sound” OR “technology” OR } \\
\text { R "memory" OR “aid” OR “cognitive” OR "assisted” OR }\end{array}$ \\
\hline $\begin{array}{l}\text { Search 6: } \\
\text { "Dementia" AND "Sundo }\end{array}$ & n" OR "Sundowning" \\
\hline Databases: & \\
\hline Database & Source \\
\hline Cinahl & www.ebscohost.com \\
\hline ISI Web of Knowledge & $\overline{\text { www.isiknowledge.com }}$ \\
\hline Ovid & http://ovidsp.uk.ovid.com/spa/ovidweb.cgi \\
\hline Ovid Embrace & http://ovidsp.ovid.com \\
\hline PubMed & http://www.pubmedcentral.nih.gov \\
\hline IEEE & http://ieeexplore.ieee.org/Xplore/guesthome.jsp \\
\hline ACM Portal & http://portal.acm.org/dl.cfm \\
\hline Swetswise & www.swetswise.com \\
\hline Google Scholar & http://scholar.google.co.uk/schhp?hl=en\&tab=ws \\
\hline $\begin{array}{l}\text { Rules: } \\
\text { - English language } \\
\text { - Articles published } \\
\text { - Abstract should be } \\
\text { - Agreement on incl }\end{array}$ & $\begin{array}{l}\text { fore } 1990 \text { were excluded } \\
\text { acluded to enable fuller analysis } \\
\text { ion/exclusion by reviewers }\end{array}$ \\
\hline
\end{tabular}

Figure 1: Database search criterion 


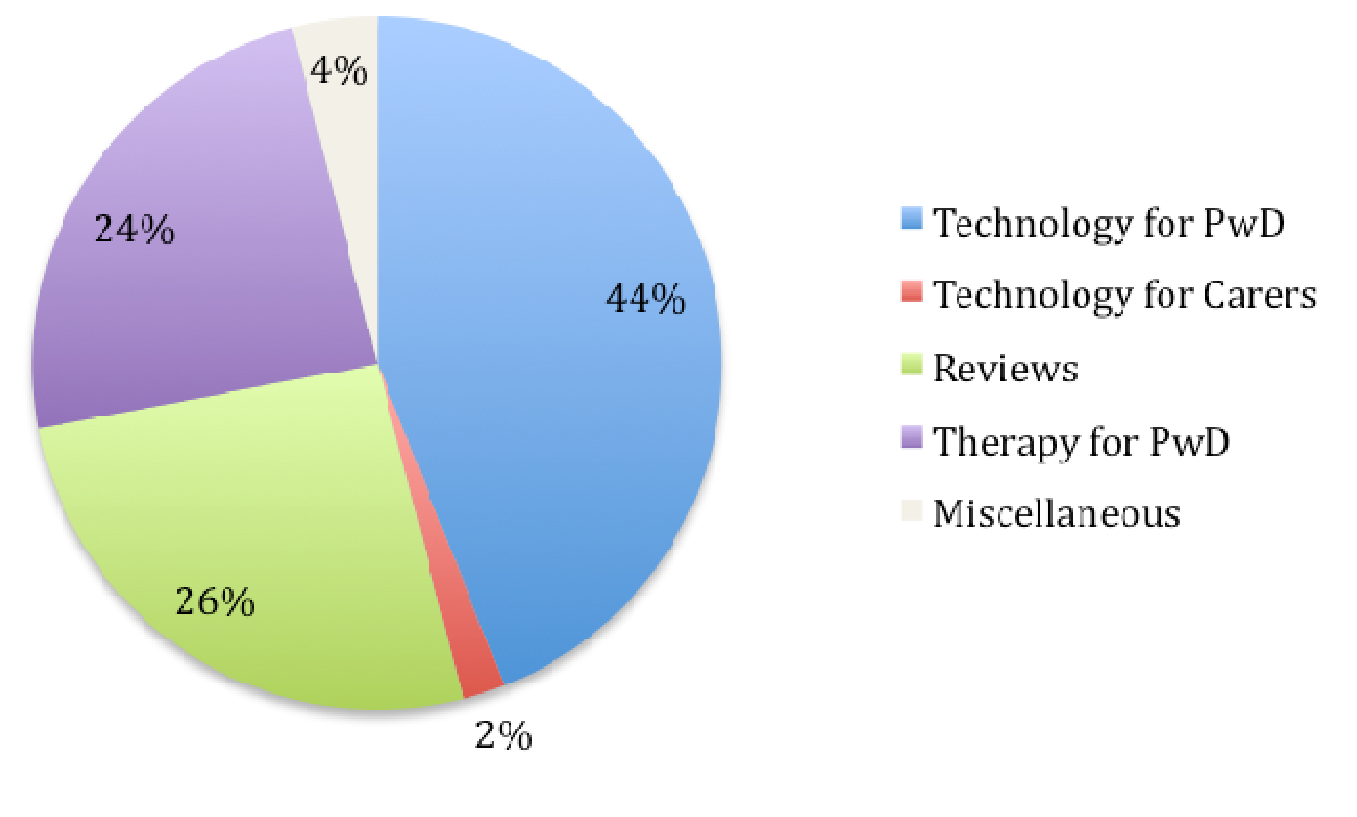

Figure 2: Paper Categories (percentages based on 54 papers)

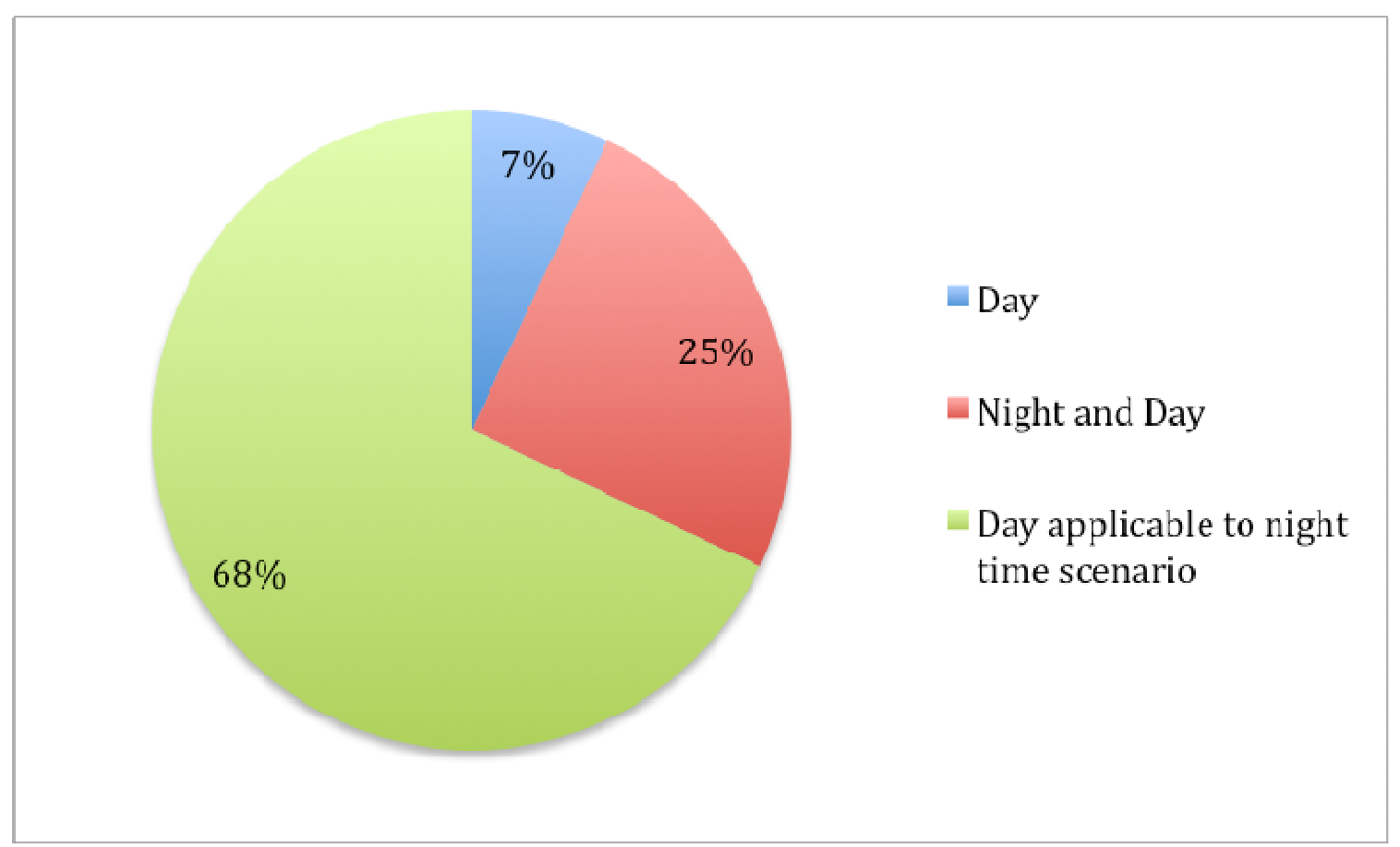

Figure 3: Paper selection categorised by application to night-time (percentages based on 54 papers) 